This item was submitted to Loughborough's Research Repository by the author.

Items in Figshare are protected by copyright, with all rights reserved, unless otherwise indicated.

\title{
Construction accident causality: learning from different countries and differing consequences
}

PLEASE CITE THE PUBLISHED VERSION

http://dx.doi.org/10.1080/01446193.2014.907498

\section{PUBLISHER}

(C) Taylor \& Francis

\section{VERSION}

AM (Accepted Manuscript)

\section{PUBLISHER STATEMENT}

This work is made available according to the conditions of the Creative Commons Attribution-NonCommercialNoDerivatives 4.0 International (CC BY-NC-ND 4.0) licence. Full details of this licence are available at: https://creativecommons.org/licenses/by-nc-nd/4.0/

\section{LICENCE}

CC BY-NC-ND 4.0

\section{REPOSITORY RECORD}

Gibb, Alistair G.F., Helen Lingard, Michael Behm, and Tracy Cooke. 2019. "Construction Accident Causality: Learning from Different Countries and Differing Consequences”. figshare. https://hdl.handle.net/2134/17785. 


\title{
Construction accident causality: learning from different countries and differing consequences
}

\author{
Gibb, A. G. F \\ ${ }^{1}$ School of Civil and Building Engineering, Loughborough University, LE11 3TU, UK (corresponding author) \\ a.g.gibb@lboro.ac.uk +44 1509223097 \\ Lingard, $\mathbf{H}$. \\ ${ }^{2}$ School of Property Construction \& Project Management, RMIT, Melbourne, 3001 VIC, Australia \\ helen.lingard@rmit.edu.au +61399253449 \\ Behm, M. \\ ${ }^{3}$ Department of Technology Systems, East Carolina University, Greenville, NC 27858-4353, USA \\ behmm@ecu.edu \\ +12523289674 \\ Cooke, $\mathbf{T}$. \\ ${ }^{2}$ School of Property Construction \& Project Management, RMIT, Melbourne, 3001 VIC, Australia \\ helen.lingard@rmit.edu.au + $\quad+61399253449$
}

\begin{abstract}
Fundamental questions remain about the practical value and generalizability of accident causation frameworks for explaining construction accidents. Relevant causality literature is reviewed; three research projects compared and implications of accident causation theories for accident investigation and analysis discussed, particularly for accidents with differing consequences and in different national contexts. The effectiveness of UK accident causality framework ConAC (Construction Accident Causality) in identifying occupational accident causes in different industry contexts (Australia and the USA) is evaluated; and the implications of the choice of theoretical framework in the analysis of construction accident causation considered. The ConAC framework was developed from a real-time analysis of 100 relatively minor construction accidents. The Australian study used this framework to analyse the National Coroners reports of 258 construction fatalities and the USA study used it to develop research instruments for interviews regarding 27 construction accidents of varying consequences. The results suggest that the ConAC framework is helpful for the analysis of the causes of accidents with outcomes of differing severity. The studies also suggest that it has international applicability despite differing occupational health and safety legislative contexts and industrial arrangements. Furthermore, significant learning can be obtained from considering underlying causes of accidents.
\end{abstract}

\section{Keywords}

Underlying accident causes, causation frameworks, accident investigation, international 


\section{Introduction}

\section{Accident causation}

Workplace safety improvements are shaped by knowledge and assumptions about how accidents happen. "What causes workplace accidents?" has been a burning question across the world, particularly in the construction industry in which accident rates remain high relative to other industries (see, for example, Safework Australia, 2012). Understanding how accidents occur is important in order to distinguish between factors that are relevant and require some action, and factors that are unimportant and can be ignored (Swuste, 2008). However, many national accident surveillance systems do not capture sufficient information to be used effectively for prevention purposes. For example, a broad classification of compensation claims by 'mechanism (e.g., 'struck by moving object, fall from height etc.) and agency of injury (e.g. mobile plant or transport) does not help us to understand the way in which an accident event 'unfolded,' the range of causal factors involved or the interplay between these causal factors (Cooke et al., 2011). Without this knowledge, the ability to develop appropriate prevention initiatives is fraught with difficulty.

In an attempt to advance a better understanding of the causes of accidents many writers have developed accident causation models or theories about how accidents happen. Accident causation models "represent, classify and efficiently organize" safety-related knowledge and provide a theoretical framework for the investigation of incidents and the identification of hazards present in a workplace (Arboleda and Abraham, p.274-275). Hollnagel (2002) describes accident causation models as a common frame of reference representing an unspoken but commonly held view of the way accidents happen. Hollnagel (2002) goes on to argue that accident causation models are helpful because they make communication and understanding more efficient. The practical usefulness of different accident causation models has been the subject of much debate and discussion (see, for example, Lehto and Salvendy, 1991).

The ability of 'generic' accident causation theories to explain accidents in different industrial contexts has been questioned as researchers have shown that accident causes vary substantially between industries (Williamson et al., 1996). Consequently, a number of construction industry-specific accident causation models have been developed in recent years. These models incorporate organizational and technological characteristics that have been empirically linked to project safety performance, such as client/owner's procurement approach (see, for example Huang and Hinze, 2006) and the design of the permanent structure (see, for example, Behm, 2005). The difference between the causal links in organizational or system incidents and occupational incidents has also been argued. Much of the work by researchers such as Reason $(1990,2006)$ focusses on organizational incidents that typically link closely to systemic failures. The difference between these two types was highlighted in the Deepwater Horizon incident in the Gulf of Mexico, where an occupational health and safety audit had declared the project site to be performing excellently, at the same time as there were significant failings in the process safety elements which then led to disastrous consequences with multiple deaths and very significant environmental impacts (Bly, 2010). This paper focusses on occupational accidents and incidents in the construction sector.

Questions have also been raised about the extent to which fatal and non-fatal occupational accidents share the same causes. It has long been conventional wisdom in work health and safety discourse that the occurrence of accidents can be represented as a triangle. For every fatal accident that occurs, there are many more non-fatal accidental injuries, and even more near-miss events (Heinrich, 1931). The 'accident pyramid' representation implies that accidents have similar causes irrespective of their outcomes. However, Salminen et al. (1992) analysed the causes of industrial accidents (some in the construction industry) and reported significantly different causes for accidents with fatal compared to non-fatal outcomes. Similarly, Li and Bai (2008) report substantial differences in the cause and circumstances surrounding fatal and non-fatal injury accidents in highway construction zones. Furthermore, Gilbertson et al (2011) argue that catastrophic accidents in construction also have different root causes.

Finally, there is emerging empirical evidence to suggest that the causes of accidents vary from country to country. Even within the UK, Cameron et al. (2008) report different causes of work accidents in the 
construction industries of England and Scotland due to differences in industry structure and the labour market in these countries.

Thus there remain fundamental questions about the practical usefulness and generalizability of accident causation frameworks and models for explaining accidents in the construction industry and, in particular, their ability to identify and expose the causal roots of the accidents further away from the incident itself.

\section{Aim}

The purpose of this comparative study was to examine the extent that a holistic framework could explain the way that causal pathways to accidents occur (in a variety of different severity types and context settings, i.e. countries), particularly to identify and explore factors further away from the incident. The accident causation framework (The ConAC framework) being considered was developed specifically for the construction industry through research funded by the UK Health and Safety Executive (HSE). This work aimed to evaluate the need for a systematic and holistic approach to understanding accident causality. The intention was not to compare the importance of each cause in these types or settings statistically. Consequently, the relative levels of importance of each causal factor in the three settings are not the focus of this paper.

The ConAC framework was developed by Haslam et al. (2003) based on a study of 100 mostly fairly minor construction accidents, categorizing causal factors as immediate accident circumstances, shaping factors and originating influences. In the United States of America, Behm and Schneller (2013) used the ConAC framework to analyse the causes of 27 construction accidents of varying degrees of severity. In Australia, Cooke and Lingard (2011) used the same framework to analyse the causes of fatal accidents in an analysis of coronial investigation reports. In this paper, data from the original ConAC study are combined with the findings of Behm and Schneller (2013) and Cooke and Lingard (2011) with the objectives of:

1. assessing the ConAC framework's value in identifying the causes of fatal and non-fatal accidents;

2. assessing the ConAC framework's value in identifying accident causes in different industry contexts (e.g. Australia and the USA); and

3. considering the implications of the choice of theoretical framework in the analysis of construction accident causation.

The following section covers relevant literature of causality before comparing the three research projects and then discussing the implications of accident causation theories for practice of accident investigation and analysis.

\section{Accident causation models and frameworks}

Katsakiori et al. (2009) classify accident models into three groups as follows:

- sequential accident models, which describe an accident as a sequence of events in a specific order;

- human information processing models, which describe accidents in terms of human behaviour and actions; and

- systemic accident models, which include organizational and management factors and describe the performance of the whole system.

Sequential models are simple linear 'cause-effect' models that describe an accident as a sequence of events that occurred in a specific order, such as the 'domino model' (Heinrich, 1931). An injury was seen as the logical conclusion of a sequence of events that commenced with a person's ancestry and social environment and culminated with a loss-producing incident. This model was updated by Bird and Loftus (1976) by incorporating the role of management in the accident process. Thus, all losses, whether they manifest in bodily injury, illness or property damage, are traced back to a lack of management control. More recently, Svenson (1991) developed the Accident, Evolution and Barrier model in which accidents are viewed as the end product of a sequence of individual 'barrier' failures. Sequential models have been criticized for focusing too much attention on the immediate circumstances surrounding an accident (Hopkins 1995) and failing to reflect the complex interaction of multiple causes in industrial accidents (Hollnagel, 2002; Goh et al., 2010).

Human information processing models explain accidents in terms of human behaviour and actions. Gordon et al. (2005) suggest that many accident reporting and analysis methods lack a firm framework for 
psychological and human factors. Following a review of accident causation theories and reporting systems, they developed a Human Factors Investigation Tool (HFIT). The HFIT model organizes accident causes into four categories: (i) the behaviours immediately prior to the accident or action errors; (ii) a reduced level of situation awareness that produced the action error; (iii) threats to safety emanating from the work environment that reduce situation awareness; and (iv) behavioural responses and detection cues that permit a recovery from error before an accident occurs.

Systemic accident causation models highlight the dynamic interaction between organizational and cultural factors in creating the conditions in which a precipitating event can result in a major incident. James Reason's 'Swiss Cheese' model is a widely cited model of this type. According to Reason $(1990,1997)$, accidents are caused by a complex interaction of latent conditions and active failures. Active failures are immediate observable causes, similar to Heinrich's (1931) unsafe acts or conditions. These can be easily identified. Also, latent conditions may also be present in work systems. In a sense these are 'accidents waiting to happen' and can include poor design, low levels of training, a mismatch between levels of competence and responsibility and other systemic deficiencies. Over time, work systems build up defences against these latent conditions. However, in local workplaces, latent conditions combine with human factors to result in human errors or violations - unsafe acts committed at the human-system interface. Reason suggests that many unsafe acts occur, but few result in accidents because systems have in-built defences, likened to layers of Swiss cheese. However, there are holes in these barriers which vary in size over time. Should a situation arise in which the holes 'line up', the system's defences fail and errors result in organizational accidents. Rasmussen et al. (1994) describe how the objectives constraints inherent in a work system, such as financial imperatives and workload demands and functional and safety requirements create boundaries of acceptable behaviour. In Rasmussen's model, pressures for production efficiency combine with a natural human tendency to seek ways of working that require the expenditure of less effort encouraging workers to "migrate" towards the boundary of acceptable performance. Safety programs establish a boundary of safe behaviour (within that which is functionally acceptable). Continual pressures to work close to the boundary indicate that, so far as possible, systems of work should be designed to be error tolerant.

\section{Construction accident causation}

Historical research on accidents in the construction industry concentrated on the analysis of data derived from existing (often compensation-based) accident reporting schemes, (see, for example, Culver, 1993; Hinze and Russell, 1995; Hunting et al., 1994; Kisner and Fosbroke, 1994; and Snashall, 1990). This approach was limited by incomplete and/or poor quality data. For example, Daniels and Marlow (2005) suggest that the level of reporting of non-fatal construction injuries in the UK construction industry is as low as 46\%. Studies by BOMEL (2001) and Gyi et al. (1999) revealed the quality of accident data collected by construction companies to be poor, limiting the ability for systematic analysis and identification of causes. The majority of early analyses of construction accident causation focused heavily on workers behaviours and attributes and the immediate surrounding circumstances of an accident. For example, Hinze (1996) identified worker distraction as a causal factor and Abdelhamid and Everett (2000) reported training, attitudes and work procedures to be the predominant causes of construction accidents. Whittington et al. (1992) identified construction company headquarters, the worksite and individual workers to be the source of accident causes in the ratio of approximately 1:2:1.

Suraji et al. (2001) developed a model of risk factors for accidents in construction operations, distinguishing between problems with workers' actions, site conditions and construction practices (proximal causes), and linking these to project, contractor and process management influences (distal causes). The role played by distal factors is now well recognized in the analysis of construction accidents. For example, Priemus and Ale (2010) use James Reason's model to explain how the systemic failure of barriers at the design, construction, permitting, inspection and use stages of the Bos and Lommerplein estate project in Amsterdam, resulted in serious structural safety problems. Manu et al. (2010) similarly refer to proximal and distal factors in their development of a method by which to analyse the extent to which various construction project characteristics contribute to accidents. These characteristics include the nature of the project, the method of construction, the extent of physical site restrictions, project duration, design complexity, the extent and nature of subcontracting arrangements, the procurement system and the level of construction (high or low 
rise). Manu et al (2010) suggest that many of these characteristics can be traced back to the clients' brief, design decisions and project management decisions.

Building on the work of Rasmussen, Mitropoulos et al. (2005) developed a systemic model of construction accident causation, which posits that the construction activity and context characteristics combine to create hazardous conditions. At the same time, production pressures elicit efficient work behaviours. However, when efficient work behaviour and hazardous situations coincide workers are exposed to hazards. According to Mitropoulos et al. (2005), hazard exposures can be mitigated by workers' efforts to control conditions and/or a tendency for competent action. When hazard exposure coincides with human error and/or changed conditions the potential for an accident is present. The incorporation of construction activity and context characteristics, which include task unpredictability, is helpful in understanding construction accidents because they reflect the constantly changing construction site environment.

Hale et al. (2012) adapted a Human Factors Analysis and Classification Scheme (HFACS), previously used in the aviation industry, to analyse the causes of construction fatalities. The HFACS framework adapted for construction classifies unsafe acts according to whether they are deliberate (violations) or errors and further subdivides each of these classifications. Thus deliberate unsafe acts can be routine, situational or exceptional and errors can be rule-based, knowledge-based or skill-based. The framework identified preconditions that could give rise to these unsafe acts, as well as organizational and environmental influences which give rise to these preconditions. HFACS framework was then used in in-depth interviews with government health and safety inspectors to explore the causes of fatal accidents. The framework was found to be particularly useful in improving accident investigators' consideration of human and organizational factors. Garret and Teizer (2009) also developed a construction safety error analysis, educational, and classification tool.

\section{The ConAC Framework}

The hierarchical ConAC framework of construction accident causality was developed as part of a three- year study by a research team based at Loughborough University in 2003 based on a study of 100 construction accidents (Haslam et al, 2003 and Gibb et al, 2006). The research team used the information obtained from people involved in selected incidents, including the victims and their supervisors, to describe the processes of accident causation in construction. The resulting model, depicted in Figure 1, identified originating influences affecting incidents in construction as including client requirements, features of the economic climate, the prevailing level of construction education, design of the permanent works, project management issues, construction processes and the prevailing safety culture and risk management approach. For example, the analysis of the 100 incidents suggested that more than half could have been prevented with alternative design solutions. Deficiencies in the risk management system were also apparent in almost all of the 100 incidents studied, which represents a significant management failure. Project management failures were also commonly reported, most of which involved inadequate attention to coordinating the work of different trades and managing subcontractors to ensure that workers on site had the requisite skills to perform the work safely. The next level of contributing causes identified in the ConAC framework is termed "Shaping factors" which include issues, such as the level of supervision provided, site constraints, housekeeping and the state of workers' health and fatigue. Poor communication within work teams was also identified as an important shaping factor. The most immediate circumstances in the ConAC framework are the suitability, usability and condition of tools and materials, the behaviour, motivation and capabilities of individual workers and features of the physical site environment, such as layout, lighting and weather conditions. While it is important to identify these immediate circumstances, the model acknowledges that construction incidents occur as a result of a complex process, involving proximal, as well as distal causes, many of which originate "upstream" of the construction site. 
Figure 1: The 'ConAC' accident causation framework (Haslam et al., 2003)

\section{Originating Influences}

client requirements, economic climate, construction education<smiles>[131IH]</smiles>

permanent works design, project management, construction processes

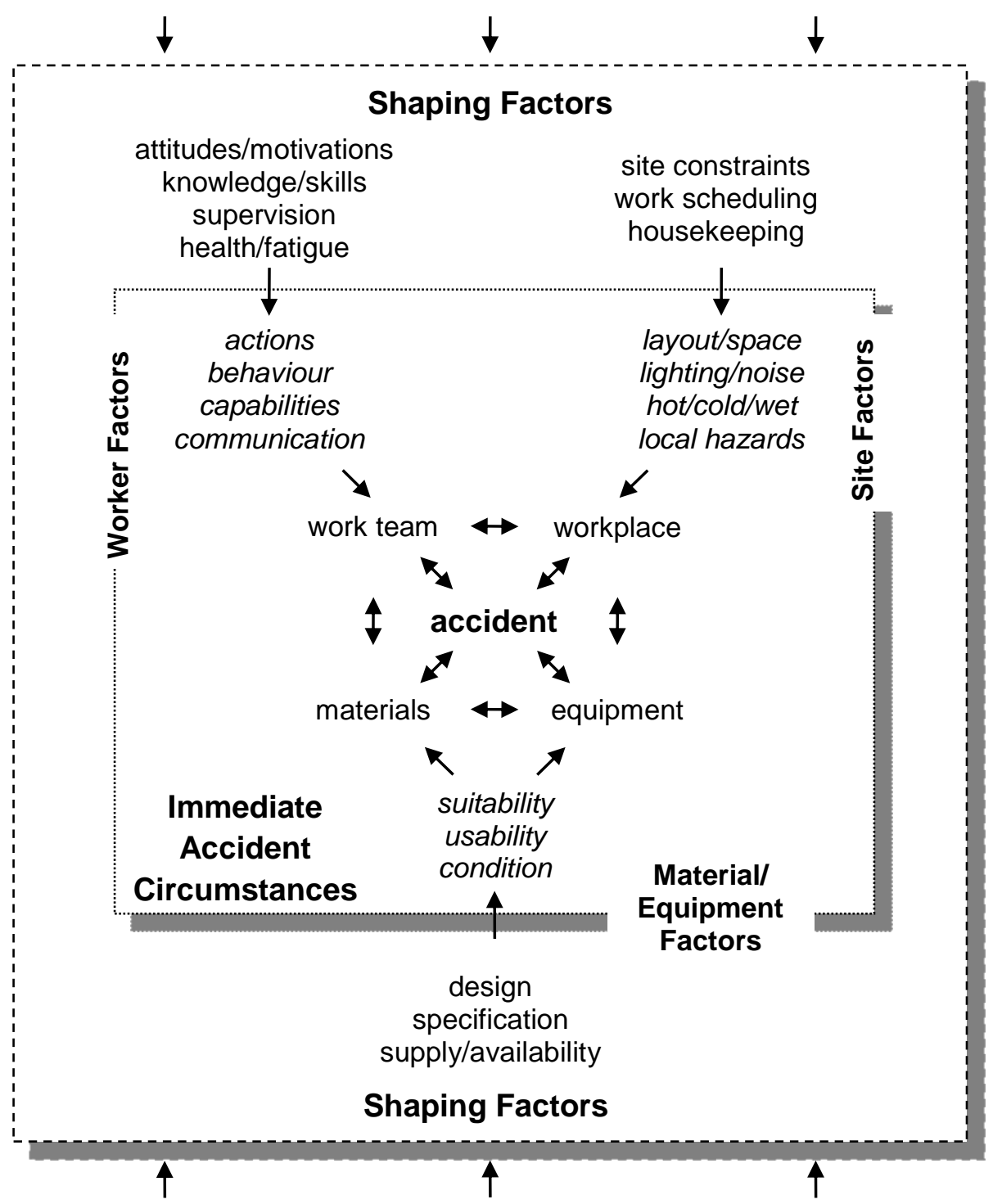

permanent works design, project management, construction processes

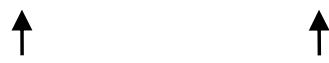

client requirements, economic climate, construction education

\section{Originating Influences}

\section{Methods}

Original ConAC framework development

The 100 ConCA construction accidents were studied in 'real-time' through a combination of interviews, focus groups, site visits, photographs and observations. Working closely with construction organizations, the team was advised when an accident had occurred. A researcher attended the accident location as soon as possible (often the following day) to make observations and to interview anyone involved in the incident and 
also other relevant site-based personnel. This initial study was evaluated by an expert panel and suitable avenues for follow-up were identified to investigate distal causal links. These included people such as designers, planners, head-office personnel and suppliers, and, where appropriate, relevant documentation was also studied. A necessary limitation of this study was that the accidents should not be ones that were being investigated by the authorities. This was to prevent witnesses being advised not to discuss the incident for fear of legal action. This worked well in that people were willing to discuss issues surrounding the accidents, but it also meant that the majority of the accidents would normally have been classed as minor, resulting in relatively low consequences. A separate exercise sought to evaluate the likelihood of the outcomes being more serious had certain key factors been different. Further detail is provided in Haslam et al. (2003).

\section{Study 1 - Australian analysis of coronial findings (Cooke \& Lingard, 2011)}

The National Coronial Information System (NCIS) is an Australian database that allows the storage and retrieval of every death investigated by an Australian coroner since July 2000, (January 2001 for Queensland). The NCIS database was searched to identify occupational accidents resulting in death in the Australian construction industry. Criteria for inclusion in the analysis were: (i) the decedent must have been a construction industry worker; and (ii) the accident resulting in death must have occurred while the decedent was at work, thus incidents in which the decedent was travelling to or from work were excluded. A total of 258 cases occurring between 2000 and 2010 were identified using these search terms and criteria. Next, thematic content analysis of coroners' findings was undertaken to code the causes of incidents that led to the deaths. Data were coded according to the categories of Immediate Causes, Shaping Factors and Originating Influences identified in the ConAC causation framework (Haslam et al., 2003). The analysis was a deductive process commencing with an identification of the immediate circumstances of the incident, e.g. the tools and materials involved, workers' behaviour and site conditions and environment. Shaping factors and then originating influences were identified wherever possible from the coroner's reports. This analysis did not assume any sequential links between immediate circumstances, shaping factors and originating influences. Thus, relevant contributing factors at each level of the ConAC framework were identified independently of those identified at the other levels. No attempt was made to link immediate circumstances with the shaping factors that preceded them, or link shaping factors with particular originating influences.

\section{Study 2 - USA analysis of non-fatal construction accidents (Behm and Schneller, 2013)}

In the USA, Behm and Schneller investigated 27 construction accidents utilizing the ConAC framework as a guide during the investigation process, which included interviews with various employees, supervisors, managers, and safety representatives (Behm \& Schneller, 2013). A variety of incidents were investigated. Thirteen of the incidents investigated (45\%) resulted in lost time ranging from one to 35 days, with an average of 5.7 lost work days. Ten of incidents investigated (38\%) resulted in medical only cases. The database contained four near misses $(15 \%)$. No fatalities were investigated. Operational definitions were created for the 22 causes/factors/influences contained within the ConAC framework and these were used to code the interview data. The analysis assumed a sequential link between relevant contributing factors identified at each level. Thus, it was assumed that immediate circumstances were causally linked to shaping factors, which were, in turn, causally linked to originating influences.

\section{Limitations}

The ConAC framework was developed inductively from the original studies of the $100 \mathrm{UK}$ accidents. The two subsequent research teams applied the ConAC model independently of each other and at different times. In their respective individual publications (Cooke \& Lingard, 2001 and Behm \& Schneller, 2013) their methodology was detailed and actions taken to ensure validity and reliability of their data was reported and documented. The three data collection settings cannot be duplicated to test inter-rater reliability or to use statistics such as Kappa. This is acknowledged as a limitation to this paper, however, the intent is to synthesize the three applications of the ConAC framework, not provide an additional check and balance of the three independent research applications. 


\section{Results}

Comparison of accident causes

Figure 2 shows the distribution of factors categorized as immediate circumstances in the ConAC framework in all three datasets (i.e., the original UK data, the Australian coronial findings and the US interview data). It is important to note that there are multiple causal links in all the incidents and so the numbers do not sum to $100 \%$. There were some similarities and some differences between the three datasets. In the original ConAC analysis, the top three ranked immediate circumstances were suitability of materials or equipment $(n=56)$, workers actions/behaviour ( $n=49)$, and workers' capabilities $(n=42)$. In comparison, in the Australian analysis, the top three ranked immediate circumstances were workers' actions/behaviour $(n=137)$, site layout/space $(n=87)$ and suitability of materials or equipment $(n=73)$. In the US analysis the top three ranked immediate circumstances were workers' actions/behaviour $(n=17)$, workers' capabilities $(n=16)$ and local hazards $(n=13)$. The UK emphasis on materials or equipment may be because the UK incidents mainly only had first aid consequences. Furthermore, the primary UK researcher had a human factors background where the consideration of the role of tools and equipment is more likely than for construction safety researchers (e.g. Vedder \& Carey, 2005 and Gibb et al., 2005). The high top score for workers actions/behaviour in the Australian case may be influenced by the fact that this study was a re-review of coroner's reports where there is often a tendency to 'blame the worker' (e.g. Kouabenan et al., 2001 and Hofmann \& Stetzer, 1998). It is also noteworthy that workers' capabilities was one of the least frequently identified immediate circumstances in the Australian analysis, identified as being relevant in only 11 cases. Local hazards were identified often in the US data compared with the UK and Australia data. In the US, the model was applied to Department of Transportation accidents where local hazards such as overhead power lines, rocks beneath soil, and steep embankments were abundant.

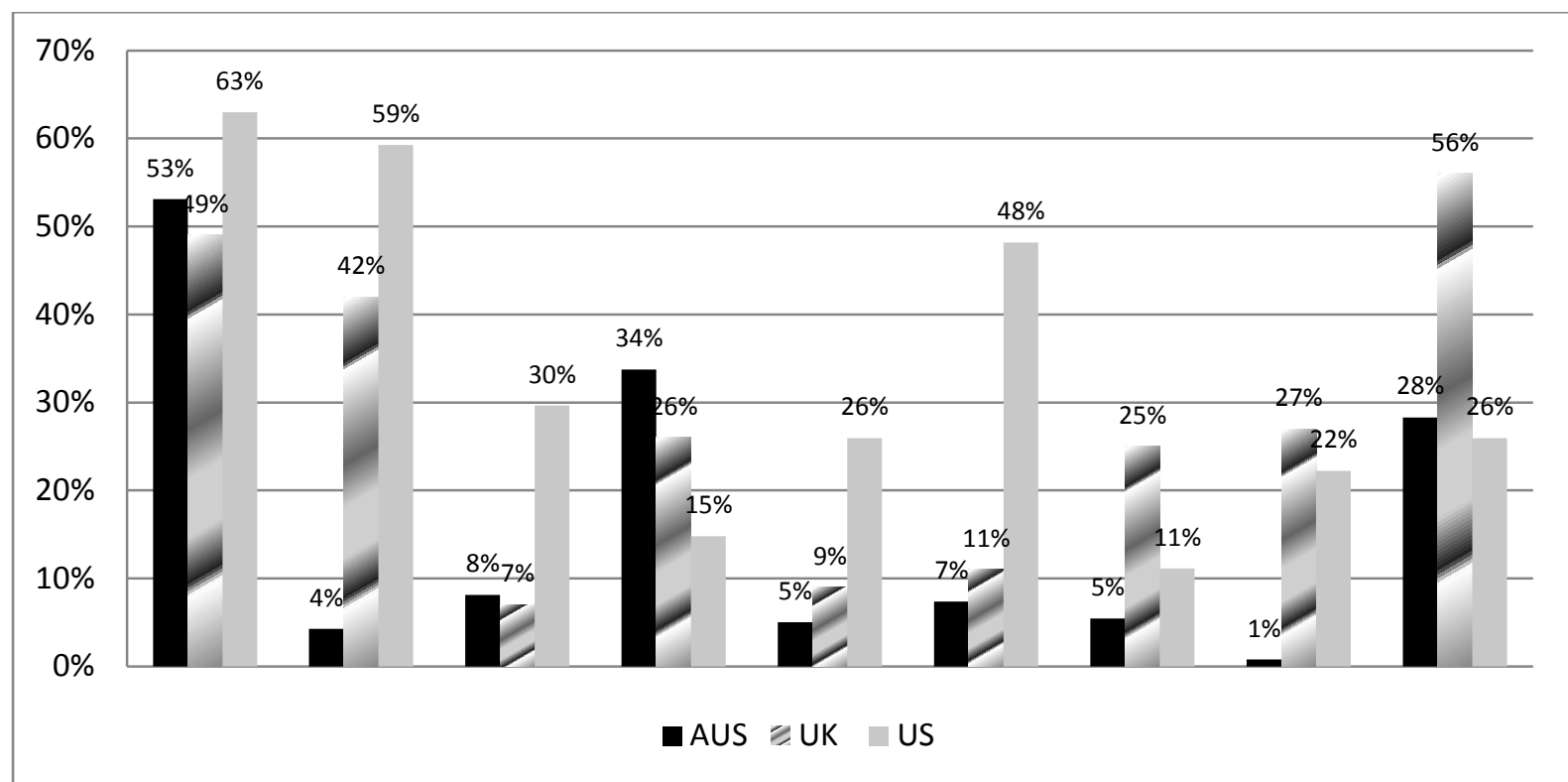

Figure 2: Distribution of immediate circumstances identified in the original Loughborough University study and the subsequent Australian and US studies.

Figure 3 shows the distribution of factors categorized as shaping factors in the ConAC framework in all three datasets (i.e., the original UK data, the Australian coronial findings and the US interview data). Again, there were some similarities and some differences between the three datasets. In the original ConAC analysis the top three ranked shaping factors were worker attitudes and motivations $(n=49)$, design or specification of materials or equipment $(n=45)$ and workers' knowledge and skills $(n=42)$, with site constraints slightly lower $(n=35)$. In the Australian analysis, the top three ranked shaping factors were workers' knowledge and skills $(n=53)$, design or specification of equipment and materials $(n=53)$ and site constraints $(n=44)$, with supervision a very close fourth $(n-42)$. In the US analysis, the top three ranked shaping factors were workers' knowledge and skills $(\mathrm{n}=16)$, workers' attitudes and motivation $(\mathrm{n}=12)$ and site constraints $(n=11)$. 


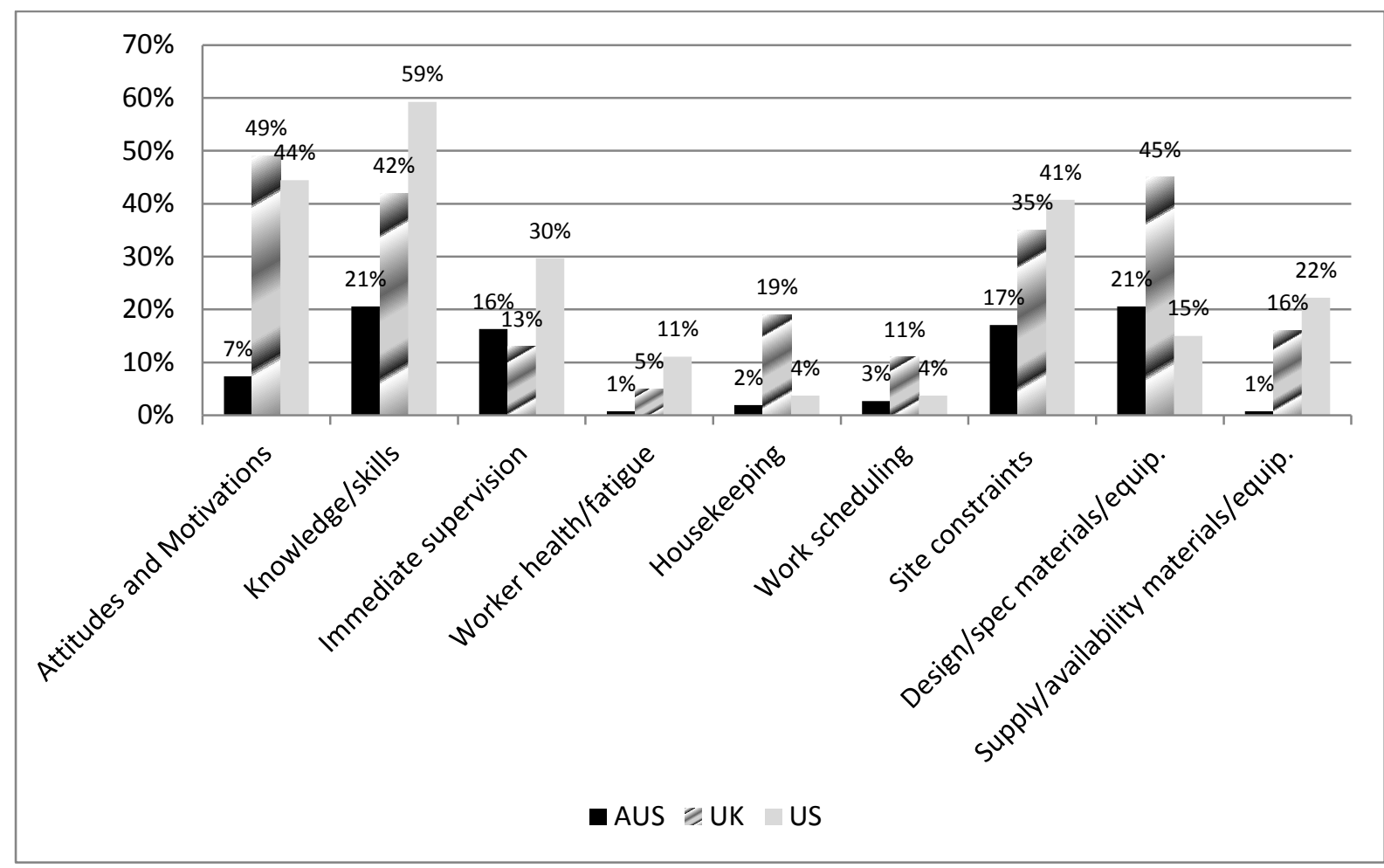

Figure 3: Distribution of shaping factors identified in the original Loughborough University study and the subsequent Australian and USA studies.

Figure 4 shows the distribution of factors categorized as originating influences in the ConAC Framework in all three datasets (i.e. the original UK data, the Australian coronial findings and the US interview data). In the original ConAC analysis the top three ranked originating influences were risk management $(n=84)$, permanent works design $(n=27)$ and project management $(n=24)$. In the Australian analysis the top three ranked originating influences were risk management $(n=54)$, construction processes $(n=30)$ and safety culture $(n=28)$. In the US, the top three ranked originating influences were risk management $(n=18)$, project management $(n=12)$ and permanent works design $(n=8)$.

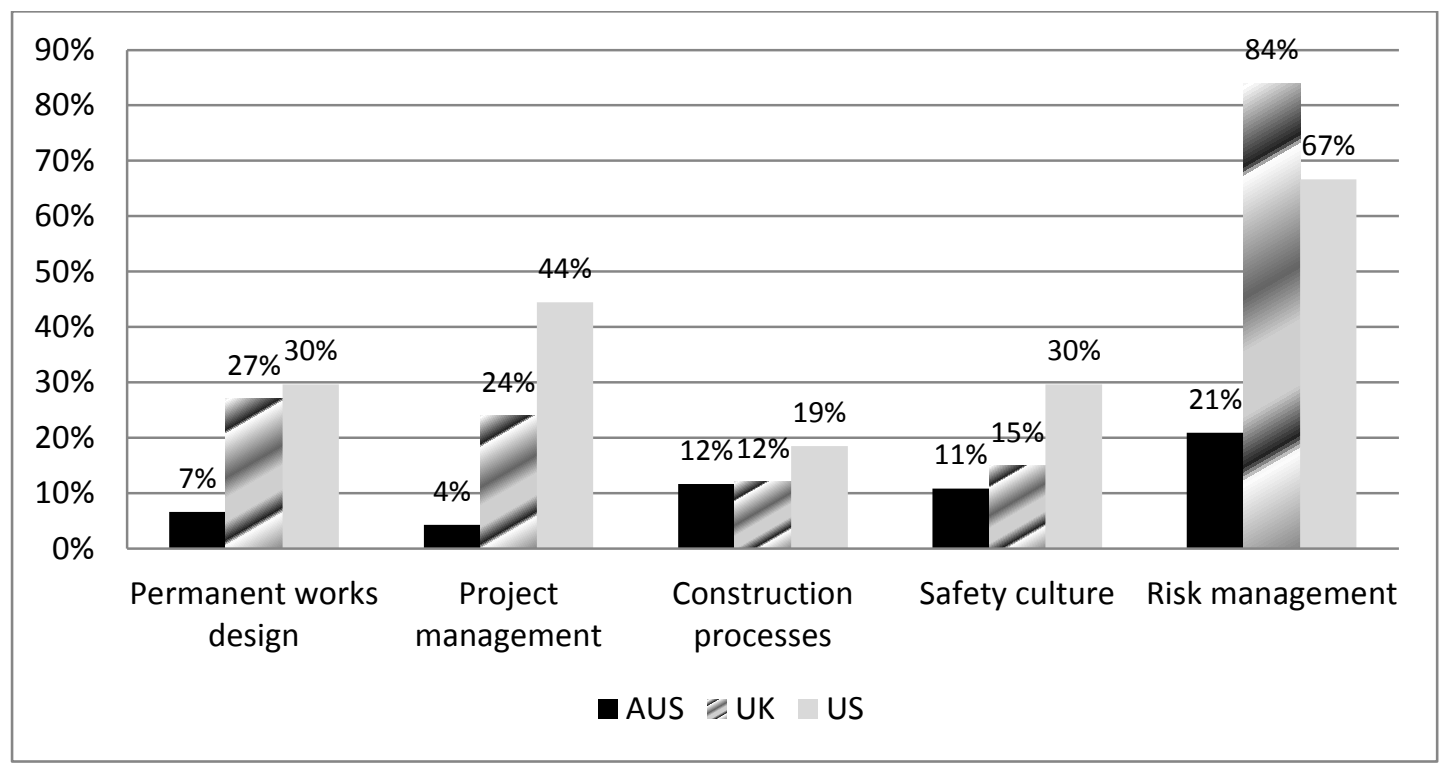

Figure 4: Distribution of originating influences identified in the original Loughborough University study and the subsequent Australian and US studies. 
Table 1 gives the average number of originating influences, shaping factors and immediate circumstances identified per accident in the three sets of data. The lowest number of originating influences per accident was identified in the Australian dataset (an average of 0.61 per accident). The US dataset yielded the highest number of originating influences per accident (an average of 1.89 per accident). The US study had the benefit of utilizing the model created from the UK study and interviewing numerous people in contrast to the Australian study. In all datasets, more immediate circumstances were identified per accident than were shaping factors or originating influences. The relationship between the number of contributing factors identified per accident and distance from the accident showed a linear inverse relationship in the Australian dataset, in both the US and UK, a greater number of originating influences were identified per accident than shaping factors.

Table 1: Number of factors identified per accident in the original Loughborough University study and the subsequent Australian and USA studies

\begin{tabular}{|l|c|c|c|}
\hline ConCA Categories & \multicolumn{3}{|c|}{ Countries } \\
\hline $\begin{array}{l}\text { Immediate } \\
\text { Circumstances }\end{array}$ & 2.47 & Australia & USA \\
\hline Shaping Factors & 0.69 & 1.82 & 3.00 \\
\hline $\begin{array}{l}\text { Originating } \\
\text { Influences }\end{array}$ & 1.35 & 1.07 & 1.74 \\
\hline
\end{tabular}

\section{Additional insight provided by the ConAC Framework}

Table 2 shows the number of times each of the causal/contributing factors identified in the ConAC framework was explicitly identified as a factor in the Australian coronial findings (column 2). This is compared with the number of times each causal/contributing factor was identified when the coronial reports were re-analysed using the ConAC framework as a guide. As can be seen, for most of the causal/contributing factors, the use of the framework led to more instances of this cause/contributing factor being identified in the coronial findings and supporting documents (e.g. police reports etc). Further, the more removed from the accident the causal/contributing factor, the greater the difference between the frequency with which the factor was identified explicitly in the coroner's report and the frequency with which it was identified in a subsequent analysis based upon the ConAC framework. Thus, the average increase in frequency of identification of immediate circumstances was $92 \%$, compared to an average increase of $188 \%$ for shaping factors and $245 \%$ for originating influences. However, this is not surprising given the legal imperative behind the coroners' reports.

Table 2: The number of times each causal/contributing factor was identified explicitly in the coronial findings and in a secondary analysis of relevant case information using the 'ConAC Framework' ( $n=258$ cases $)$

\begin{tabular}{|c|c|c|c|c|}
\hline & Cause/contributing factor classification & $\begin{array}{l}\text { Number of } \\
\text { times the } \\
\text { factor was } \\
\text { recorded } \\
\text { explicitly } \\
\text { in the } \\
\text { coroners' } \\
\text { findings } \\
\end{array}$ & $\begin{array}{c}\text { Additional } \\
\text { times the factor } \\
\text { was identified } \\
\text { as being } \\
\text { relevant when } \\
\text { using the } \\
\text { 'ConAC' } \\
\text { Framework }\end{array}$ & $\begin{array}{l}\text { Per cent } \\
\text { increase }\end{array}$ \\
\hline \multirow{9}{*}{ 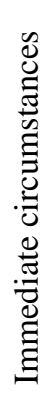 } & Worker actions/behaviour & 64 & 73 & 114 \\
\hline & Worker capabilities (including new knowledge/skills) & 5 & 6 & 120 \\
\hline & Communication & 11 & 10 & 91 \\
\hline & Site layout/space & 30 & 50 & 167 \\
\hline & Working environment (lighting/noise/hot/cold/wet) & 8 & 5 & 63 \\
\hline & Site conditions (excluding equipment and materials) & 0 & 0 & 0 \\
\hline & Local Hazards & 7 & 12 & 171 \\
\hline & Condition of materials or equipment & 7 & 7 & 100 \\
\hline & Usability of materials or equipment & 2 & 0 & 0 \\
\hline
\end{tabular}




\begin{tabular}{|c|c|c|c|c|}
\hline & Suitability of materials or equipment & 38 & 35 & 92 \\
\hline \multirow{10}{*}{ 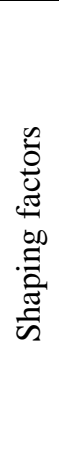 } & Attitudes and Motivations & 8 & 11 & 138 \\
\hline & Knowledge/skills & 23 & 30 & 130 \\
\hline & Immediate supervision & 18 & 24 & 133 \\
\hline & Worker health/fatigue & 0 & 2 & NA \\
\hline & Housekeeping & 2 & 3 & 150 \\
\hline & Work scheduling & 2 & 5 & 250 \\
\hline & Site constraints & 9 & 35 & 389 \\
\hline & Design & 12 & 38 & 317 \\
\hline & Specification & 3 & 0 & 0 \\
\hline & Supply/availability & 0 & 2 & NA \\
\hline \multirow{8}{*}{ 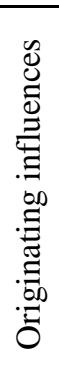 } & Permanent works design & 4 & 13 & 325 \\
\hline & Project management & 4 & 7 & 175 \\
\hline & Construction processes & 6 & 24 & 400 \\
\hline & Safety culture & 8 & 20 & 250 \\
\hline & Risk management & 14 & 40 & 286 \\
\hline & Client requirements & 2 & 5 & 250 \\
\hline & Construction education & 11 & 3 & 27 \\
\hline & Economic climate & 0 & 1 & NA \\
\hline
\end{tabular}




\section{Discussion}

\section{Applicability of the ConAC Framework}

The results suggest that the ConAC construction accident causation framework can be used to analyse the causes of accidents resulting in outcomes of different levels of severity. The framework was initially developed using interview data exploring the causes of minor (mostly first aid only) accidents. However, the majority of contributing factors reflected in the framework were identified as relevant to a greater or lesser extent in the analysis of causes of more serious non-fatal and fatal accidents. Further, in all three datasets immediate circumstances, shaping factors and originating influences could be identified for many of the accidents. The relevance of the framework to the causes of accidents in construction industries in both Australia and the USA also suggests that it has international applicability. It is noteworthy that the USA and Australia have significantly different occupational health and safety legislative frameworks and industrial arrangements (Lingard, 2012), but this study suggests that the causal relationships are not significantly affected.

In Brazil, Filho et al. (2012) analysed organizational factors utilizing the terminology from the original research (Haslam et al., 2005) that underpinned the development of the ConAC framework. They focused on fall accidents during residential apartment construction and found they could trace risk reduction deficiencies to organizational influences including design decisions and project planning and management. Their work reinforces the utility of the ConAC framework and the importance of investigating upstream activities.

\section{What-you-look-for-is-what-you-find}

Hollnagel (2002) comments that one disadvantage associated with accident causation models is that a single point of view is strongly favoured and alternative explanations may not be considered. Lundberg et al. (2009) raised the issue of WYLFIWYF ('What-You-Look-For-Is-What-You-Find), arguing that the models used in any investigation are going to heavily influence the outcome. It is therefore logical to assume that, where people have only looked for immediate accident causes, then that is what they will find.

This research results support the WYLFIWYF principle. It is noteworthy that fewer originating influences per accident were identified in the Australian dataset compared to the US or UK datasets. The Australian analysis utilized a secondary source (coronial findings and associated documents) which were contained in a national database. There was considerable variation in the depth or analysis of coronial findings and data capture and reporting practices varied widely between Australian states and territories. The coronial investigations and subsequent reports that were produced were not informed by the ConAC framework and there was no opportunity for researchers to interview the accident investigators or the people directly involved in the accidents. In contrast, the UK and US studies were interview-based and researchers had the opportunity to explore the relevance of distal causes. The US researcher used the ConAC framework to guide his interviews with people who had been personally involved in the incident, their supervisors and managers, those who had witnessed the workplace accident, and the organization's safety professional. Thus, the US researcher was actively 'looking for' the ConAC factors. The WYLFIWYF principle is also supported by the fact that, when the Australian researchers' reviewed all of the documents contained in the NCIS database pertaining to the identified construction work-related deaths, they were able to identify substantially more contributing factors than were identified in the coronial findings themselves. It is possible that were a systemic accident causation model, such as the ConAC framework, to be used to inform investigations, a more comprehensive range of contributing factors could be identified enabling more robust accident prevention strategies. Further, the use of a consistent accident causation model could overcome problems associated with accident data quality and coding.

\section{The value of the ConAC Framework}

By necessity, many accident causation models and frameworks have been derived from relatively small sample sizes such that influences factors including consequence severity, industry sector, project-type, national context, investigation protocols are not able to be taken into consideration. The more popular models then tend to be used, sometimes inappropriately, outside of their initial context. For example, Reason comments that "enthusiastic use [of the Swiss Cheese model] sometimes relied on interpretations of 
the model's semantics that went rather far beyond what was initially intended" (Reason et al., 2006). Svenson et al. (1999) argue that accident investigators from different professional backgrounds will come to different conclusions as they will interpret the 'facts' from their own theoretical perspectives. They go on to say that "experts with different basic professional training should perform accident analyses jointly and not in sequence or in parallel. Contrary to this view, this current exercise has demonstrated the value of a preexistent causal framework to inform the investigation process.

A significant reason for investigating accidents is to learn from past mistakes and reduce the incidence of future accidents (Lindberg et al., 2010; Chua and Goh, 2004), hence the benefit of exploring contributing factors further up the causal chain. However, often, accident investigations only concentrate on the immediate circumstances, due to the need to prosecute offenders or limitations in time and resources for the investigation. Seasoned accident researcher James Reason argues that the "definition of a root cause is the contributing factor that you were working on when the money or time runs out" (Reason et al., 2006). The results of the US and Australian studies presented here suggest the value of the ConAC framework to construction accident investigators, particularly in exploring 'distal' causes which may not be immediately obvious. Using the ConAC framework, the Australian researchers were able to identify more factors contributing to fatal construction accidents than were identified in existing coronial investigation reports. Also, the number of additional contributing factors that could be identified using the ConAC framework increased proportionally with distance from the accident. Thus, proportionally fewer additional immediate circumstances were identified than shaping factors or originating influences. This suggests that investigations tend to focus on immediate circumstances but may not adequately identify 'blunt end' contributing factors. Mitropoulos et al. (2005) comment that most accident investigations focus on immediate circumstances because their purpose is to assign blame rather than support learning lessons for prevention. Similarly, Hale et al. (2012) note the tension between enforcement and the need to learn from accidents for prevention purposes.

There are, of course, problems with moving further away from the circumstances immediate to the accident and focusing on more distal factors. In his seminal work on major, catastrophic accidents, Reason revised his terminology between the first 'Swiss Cheese Model' (1990 p.208), which spoke of latent errors or failures, to latent conditions (Reason et al., 2006). He writes "A condition is not a cause, but it is necessary for a causal factor to have an impact. Oxygen is a necessary condition for fire; but its cause is a source of ignition" (Reason et al., 2006). Thus, apportioning blame, particularly within a legal framework is significantly different from establishing a causal link. The combined research results suggest that the ConAC framework is useful for establishing 'distal' factors that contributed to an accident but it would be problematic and inappropriate to use the model to attribute blame. Accident investigations have the benefit of hindsight; those who consider hindsight as always being equivalent to reasonably foreseen are mistaken. The fundamental purpose of accident investigations is for organizational learning (Lindberg et al., 2010); Sklet, 2004). Notwithstanding, such a model could also be used in targeting initiatives for improving health and safety performance.

\section{Conclusions}

This paper has shown how a generic framework developed in the UK from a real-time analysis of 100 relatively minor construction accidents was used in the analysis of Australian National Coroners reports of 258 construction fatalities and the study of 27 construction accidents of varying consequences in the USA.

The results suggest that the ConAC framework can help to analyse the causes of accidents resulting in outcomes of different levels of severity. The framework was initially developed using interview data exploring the causes of minor (mostly first aid only) accidents. However, in all three datasets immediate circumstances, shaping factors and originating influences could be identified for many of the accidents. The distribution of factors within these groupings was not consistent across the three settings, but each group was clearly represented. The ConAC framework allows investigators to question conditions throughout the lifecycle of typical construction projects, from the sharp end on site to the underlying distal factors. The framework allows investigators to learn about conditions and potential risk countermeasures that should be considered in an overall construction safety and health management system. The research synthesis shows that similar conditions, as outlined in the ConAC framework, exist for a variety of construction accidents 
with a variety of outcomes from near misses to fatalities. This challenges some current theory in that these findings are counter to that of previously published research findings reporting that fatalities and minor injuries have different causes. We contend that the ConAC framework's terminology is sufficiently generalizable and because it focuses on conditions rather than mechanism or agency of injury, it can be applied to a variety of construction accident consequences and yield numerous organizational learning opportunities at both the sharp end on site and the blunt end of project management or design.

The relevance of the ConAC framework to the causes of accidents in construction industries in both Australia and the USA also suggests that it has international applicability, despite the differences in the occupational health and safety legislative contexts and industrial arrangements in the different countries.

The findings show that significant learning can be obtained from considering underlying causes of accidents to reduce the incidence of future accidents. Most current incident investigation protocols concentrate on immediate accident circumstances rather than exploring contributing factors further up the causal chain, often due to the need to prosecute offenders or limitations in time and resources for the investigation. The authors have argued in support of the WYLFIWYF concept (What You Look For Is What You Find) which can potentially limit the increased understanding of underlying root causes of accidents if the search for causes does not go beyond immediate circumstances. Although not every construction accident investigation will reveal contributing factors up the causal chain, we contend that, in practice, when investigations of construction accidents do not reveal any shaping factors or originating influences, the investigation should be scrutinized. The authors acknowledge however that the WYLFIWYF concept also challenges the assertions of this work in that it would suggest that if you look for distal causes then you will find them.

There was agreement between the three data sets when considering circumstances immediately surrounding the incidents. However, the more removed from the accident the causal/contributing factor, the greater the difference between the frequency with which the factor was identified explicitly in the coroner's reports and the US study.

The implications of these findings are that, in order to understand better the complex multi-causal links in construction accidents, organisations and governments should be encouraged to investigate beyond the immediate circumstances. The combined research results suggest that a causal framework such as ConCA is useful for establishing 'distal' factors that contributed to an accident, despite is comparative complexity. However, it would be problematic and inappropriate to use the framework to attribute blame or as the basis for prosecution. Further research into applications of causality frameworks beyond the context on which they are based is required to explore this aspect more fully. The Australian application of the ConAC model attempted to identify the outer Originating Influences of client requirements, economic climate, and construction education whereas the original model development and the US application did not quantitatively capture these distal factors. We encourage construction researchers and practitioners to consider these important antecedents and the complex nature of construction industry relationships when seeking to understand occupational safety and health in the built environment.

\footnotetext{
References

Abdelhamid, T.S. and Everett, J.G. (2000) Identifying Root Causes of Construction Accidents. Journal of Construction Engineering and Management, 126 (1), 52-60.

Arboleda, C. A. and Abraham, D. M. (2004) Fatalities in trenching operations - analysis using models of accident causation, Journal of Construction Engineering and Management, 130 (2), 273-280.

Attwood, D., Khan, F. and Veitch, B. (2006) Occupational accident models - where have we been and where are we going? Journal of Loss Prevention in the Process Industries, 19, 664-682

Behm, M. (2005) Linking Construction Fatalities to the Design for Construction Safety Concept. Safety Science. 43 (8), $589-611$.

Behm, M. and Schneller, A. (2013) Application of the Loughborough Construction Accident Causation Model: A Framework for Organizational Learning. Construction Management and Economics. 31 (6), 580-595, DOI:10.1080/01446193.2012.690884.

Bird, F. E. and Loftus, R. G., (1976) Loss Control Management, Institute Press, Loganville, USA.

BOMEL (2001) Improving health and safety in construction - Phase 1: data collection, review and structuring. Health and Safety Executive Contract Research Report 387/21 (HSE Books: Sudbury, Suffolk).

Bly, M. (2010) Deepwater Horizon Accident Investigation Report, Diane Publishing, Darby PA, USA, 191 pp.
} 
Cameron, I., Hare, B. and Davies, R. (2008) Fatal and major construction accidents: A comparison between Scotland and the rest of Great Britain, Safety Science, 46, 692-708.

Chua, D. K. H. and Goh, Y. M. (2004) Incident Causation Model for Improving Feedback of Safety Knowledge. Journal of Construction Engineering and Management, 130 (4), 542-551.

Cooke, T. and Lingard, H., (2011), A retrospective analysis of work-related deaths in the Australian construction industry, in ARCOM Twenty-Seventh Annual Conference, Conference Proceedings, Bristol, 279-288.

Culver, C. (1993) Analysis of construction accidents: the workers' compensation database. Professional Safety, 38 (3), $22-27$.

Daniels, C. and Marlow, P. (2005) Literature review on the reporting of workplace injury trends, HSL/2005/36, Health and Safety Laboratory, HSE, London.

Filho, J.M.J., Fonseca, E.D., Lima, F.P.A., and Duarte, F.J.C.M. (2012) Organizational factors related to occupational accidents in construction. Work, 41, 4130-4136.

Garrett, J. W. and Teizer, J. (2009) Human Factors Analysis Classification System Relating to Human Error Awareness

Taxonomy in Construction Safety. Journal of Construction Engineering and Management, 135 (8), $754-763$.

Gibb, A.G.F., Haslam, R.A., Hide, S., Gyi, D.E. \& Duff, A.R. (2006) What causes accidents, Civil Engineering, Proceedings of the Institution of Civil Engineers, Vol. 159, Special Issue 2, pp. 46-50, ISSN 0965089 X

Gibb, A.G.F., Hide, S., Haslam, R.A., Gyi, D.E., Atkinson, S. and Duff, R. (2005) Construction tools and equipment - their influence on accident causality, Journal of Engineering Design \& Technology (JEDT), 3 (1), 12-23, ISSN 1726-0531

Gilbertson, A., Kappia, J., Bosher, L. and Gibb, A.G.F. (2011) Preventing catastrophic events in construction, RR834, Health \& Safety Executive, HSE Books, 220pp.

Goh, Y. M., Brown, H. and Spickett, J. (2010) Applying systems thinking concepts in the analysis of major incidents and safety culture, Safety Science, 48, 302-309.

Gordon, R., Flin, R. and Mearns, K. (2005) Designing and evaluating a human factors investigation tool (HFIT) for accident analysis, Safety Science, 43, 147-171.

Gyi, D.E., Gibb, A.G.F. and Haslam, R.A. (1999) The quality of accident and health data in the construction industry: interviews with senior managers, Construction Management and Economics, 17, 197-24.

Hale, A., Walker, D., Walters, N. and Bolt, H. (2012) Developing the understanding of underlying causes of construction fatal accidents, Safety Science, 50 (10), 2020-2027

Haslam, R.A., Hide, S.A., Gibb, A.G.F., Gyi, D.E., Atkinson, S., Pavitt, T.C., Duff, R. \& Suraji, A. (2003) Causal factors in construction accidents, Health and Safety Executive, HSE Report RR 156, 222 pp, ISBN 0717627497.

Heinrich, H. (1931) Industrial Accident Prevention: a Scientific Approach, McGraw-Hill, New York, p. 91.

Heinrich H. W., Petersen D., and Roos N. (1980) Industrial accident prevention: A safety management approach (McGraw-Hill: New York), 5th edition.

Hofmann, D.A. and Stetzer, A. (1998) The role of safety climate and communication in accident interpretation: implications for learning from negative events, Academy of Management Journal, 41 (6), 644-657, doi: 10.2307/256962.

Hopkins, A. (1995) Making safety work: Getting management commitment to occupational health and safety, Allen \& Unwin, St Leonards,

Hinze, J. (1996) The distraction theory of accident causation. Proceedings of the International Conf. on the Implementation of Safety and Health on Construction Sites, CIB W99. L. Alvez Diaz and R. Coble eds, Balkema, Rotterdam, The Netherlands, 375384.

Hinze, J. and Russell, D. B. (1995) Analysis of fatalities recorded by OSHA. Journal of Construction Engineering and Management, 121, 29-214

Hollnagel, E. (2002) Understanding accidents - from root causes to performance variability. Paper presented at the 7th IEEE Human Factors Meeting, Institute of Electrical and Electronics Engineers. Scottsdale, Arizona.

Huang, X. and Hinze, J. (2006) The Owner's Role in Construction Safety. ASCE Journal of Construction Engineering and Management, 132 (2), February, 164-173. American Society of Civil Engineers, doi: 10.1061/(ASCE)0733-

9364(2006)132:2(164)

Hunting, K.L., Nessel-Stephens, L., Sanford, S.M., Shesser, R., and Welch, L.S. (1994) Surveillance of construction worker injuries through an urban emergency department. Journal of Occupational Medicine, 36, 356-364

Katsakiori, P., Sakellaropoulos, G. and Manatakis, E. (2009) Towards an evaluation of accident investigation methods in terms of their alignment with accident causation models, Safety Science, 47, 1007-1015.

Kisner, S.M. and Fosbroke, D.E., (1994) Injury hazards in the construction industry. Journal of Occupational Medicine, 36, 137143 .

Kouabenan, D.R., Medina, M., Gilibert, D. and Bouzon, F. (2001) Hierarchical Position, Gender, Accident Severity, and Causal Attribution, Journal of Applied Social Psychology, 31 (3), 553-575.

Lehto, M. and Salvendy, G. (1991) Models of accident causation and their application: Review and reappraisal, Journal of Engineering and Technology Management, 8, 173-205.

Li, Y. and Bai, Y., (2008) Comparison of characteristics between fatal and injury accidents in the highway construction zones, Safety Science, 46, 646-660.

Lindberg, A., Hansson, S. and Rollenhagen, C. (2010) Learning from Accidents - What More Do We Need to Know? Safety Science 48 (6), 714-721.

Lingard, H. (2012) Occupational health, safety and workers' wellbeing, accepted for publication in A. Dainty and M. Loosemore, Human resource management in construction: Critical perspectives, ( $2^{\text {nd }}$ Edition), Routledge, London. 10-162.

Lundberg, J., Rollenhagen, C. and Hollnagel, E. (2009) What-You-Look-For-Is-What You-Find-The Consequences Of

Underlying Accident Models In Eight Accident Investigation Manuals. Safety Science, 47 (10), 1297-1311.

Manu, P., Ankrah, N., Proverbs, D. and Suresh, S. (2010) An approach for determining the extent of contribution of construction project features to accident causation, Safety Science, 48, 667-692. 
Mitropoulos, P., Abdelhamid, T. S. and Howell, G. A., (2005) Systems model of construction accident causation, Journal of Construction Engineering and Management, 131, 816-824.

Priemus, H. and Ale, B. (2010) Construction safety: An analysis of systems failure The case of the multifunctional Bos \& Lommerplein estate, Amsterdam, Safety Science, 48, 111-122.

Rasmussen, J., Pesdersen, O. M. and Goodstein, L. P., (1994) Cognitive system engineering, Wiley, New York.

Reason, J. (1990) Human Error, Cambridge University Press, 302 pp., ISBN 0521314194.

Reason, J. (1997) Managing the risks of organizational accidents, Ashgate Publishing, 252 pp., ISBN 1840141050.

Reason, J., Hollnagel, E. and Paries, J. (2006) Revisiting the Swiss Cheese model of accidents, Project Safbuild - EEC Note No. 13/06, Eurocontrol - European Organisation for the Safety of Air Navigation, 25pp.

Safe Work Australia (2012) Compendium of Workers' Compensation Sttistics Australia, 2009-10.March 2012: Canberra. ISBN 978-0-642-33332-2

Salminen, S., Saari, J., Saarela, K.L. and Räsänen, T. (1992) Fatal and non-fatal occupational accidents: identical versus differential causation, Safety Science, 15, 109-118.

Sklet, S. (2004) Comparison of some selected methods for accident investigation, Journal of Hazardous Materials, 111(1-3), 2937.

Snashall, D. (1990) Safety and health in the construction industry. British Medical Journal, 31, 563-564.

Suraji, A., Duff, A.R. and Peckitt, S.J. (2001) Development of causal model of construction accident causation, Journal of Construction Engineering and Management, 127, 337-344.

Svenson, O. (1991) The accident evolution and barrier function (AEB) model applied to incident analysis in the processing industries, Risk Analysis, 11, 499-507.

Svenson, O., Lekberg, A. and Johansson, A.E.L. (1999) On perspective, expertise and differences in accident analyses: arguments for a multidisciplinary integrated approach, Ergonomics, 42, 1561-1571

Swuste, P. (2008) "You will only see it, if you understand it" or occupational risk prevention from a management perspective, Human Factors and Ergonomics in Manufacturing, 18, 438-453.

Vedder, J. and Carey, E. (2005) A multi-level systems approach for the development of tools, equipment and work processes for the construction industry, Applied Ergonomics, 36 (4), 471-480.

Whittington C., Livingston A. and Lucas D.A. (1992) Research into management, organisational and human factors in the construction industry. HSE Contract Research Report 45/1992 (HMSO: London).

Williamson, A. M., Feyer, A.-M. and Cairns, D. R. (1996) Industry differences in accident causation, Safety Science, $24,1-12$. 